\title{
Classification of batik patterns using K-Nearest neighbor and support vector machine
}

\author{
Agus Eko Minarno, Fauzi Dwi Setiawan Sumadi, Hardianto Wibowo, Yuda Munarko \\ Informatics Engineering, Universitas Muhammadiyah Malang, Indonesia
}

\begin{tabular}{l} 
Article Info \\
\hline Article history: \\
Received Aug 1, 2019 \\
Revised Nov 4, 2019 \\
Accepted Dec 10, 2020 \\
\hline Keywords: \\
Batik \\
Gray level co-occurrence \\
matrix (GLCM) \\
Image processing \\
KNN \\
SVM
\end{tabular}

Article Info

Article history:

Received Aug 1, 2019

Revised Nov 4, 2019

Accepted Dec 10, 2020

\section{Keywords:}

Gray level co-occurrence

matrix (GLCM)

KNN

\begin{abstract}
This study is proposed to compare which are the better method to classify Batik image between K-Nearest neighbor and support vector machine using minimum features of GLCM. The proposed steps are started by converting image to grayscale and extracting colour feature using four features of GLCM. The features include energy, entropy, contras, correlation and $0^{\circ}$, $45^{\circ}, 90^{\circ}$, and $135^{\circ}$. The classifier features consist of 16 features in total. In the experimental result, there exist comparison of previous works regarding the classification KNN and SVM using multi texton histogram (MTH). The experiments are carried out in the form of calculation of accuracy with data sharing and cross-validation scenario. From the test results, the average accuracy for $\mathrm{KNN}$ is $78.3 \%$ and $92.3 \%$ for SVM in the cross-validation scenario. The scenario for the highest accuracy of data sharing is at $70 \%$ for $\mathrm{KNN}$ and at $100 \%$ for SVM. Thus, it is apparent that the application of the GLCM and SVM method for extracting and classifying batik motifs has been effective and better than previous work
\end{abstract}

This is an open access article under the CC BY-SA license.

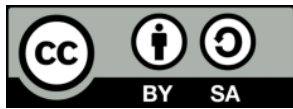

\section{Corresponding Author:}

Agus Eko Minarno,

Informatics Engineering,

Universitas Muhammadiyah Malang, Indonesia.

Email: aguseko@umm.ac.id

\section{INTRODUCTION}

Indonesia is famous for its arts and culture which are spread throughout the territory of Indonesia, by which each region has different arts and cultures, due to a diverse situation, condition and environment. One of the famous works of arts originating from Indonesia is prominently known as batik, identified as a traditional pattern on cloth drawn with traditional methods. In Javanese, batik means drawing a point on a cloth, as it is derived from the words: "ngembat" (writing) and "titik" (dot) [1]. Batik as one of the famous arts and cultures originating from Indonesia has its own characteristics depending on its place of origin. Unfortunately, most Indonesian wear batik motifs due to its attracting colour and pattern without knowing the name of the used motif, the origin of the motif, or the philosophy contained in the motif due to a wide range of batik patterns in Indonesia.

Several studies have been conducted previously for pattern recognition and image classification both for image retrieval and image classification system [2-4]. Kurniawardhani et al. [5] proposed an invariant feature extraction method for rotation by using the combination of extraction method, which compared the method of combining LBPROT-CLBP_M with LBPROT-CRLBP_M. From the results of the research, the LBPROT-CRLBP_M method could increase the accuracy by approximately $30 \%$ with a maximum accuracy of $90 \%$. The other issue about classification using $\mathrm{KNN}$ was also proposed by [6, 7]. Minarno et al. [8] combining the grey level co-occurrence matrix (GLCM) method with discrete wavelet transform (DWT) to classify batik images, which were named as co-occurence matrix of sub-band images. 
Arebey et al. [9] used the GLCM, KNN and multi-layer perception (MLP) methods to detect and classify solid waste levels. From the results of the research, the KNN method gave better results compared to the MLP method. Nurhida et al. [10] compared the performance of the GLCM method, Canny Edge Detection, and Gabor for extraction of batik features, showing that the GLCM method had the best performance with classification accuracy reaching 80\%. Minarno et al. [11] compared performance for precision and recall among the GLCM method, multi texton histogram (MTH), MTH + GLCM and the multi texton co-occurrence descriptor (MTCD). Meanwhile, Fahrurozi et al. [12] combined the GLCM method with several edge detection methods to perform feature extraction on wood fibres. Chai et al. [13] applied the GLCM method to identify fractures in the bone, gaining accuracy of $86.67 \%$. In addition, research conducted by [14-16] used the GLCM method as feature extraction. Raheja et al. [17] used the GLCM method to detect defects in fabric. Mitrea et al. [18] used the GLCM method in diagnosing liver tumours in ultrasound images. Fakhira et al using SVM to classify knots timber using $400 \mathrm{x}$-ray dataset and the highest accuracy is $76 \%$.

This study is proposed to compare which are the better method to classify Batik image between K-Nearest neighbor and support vector machine using minimum features of GLCM. The proposed steps are started by converting image to grayscale and extracting colour feature using four features of GLCM. The features include energy, entropy, contras, correlation and $0^{\circ}, 45^{\circ}, 90^{\circ}$ and $135^{\circ}$. The total features utilized on the classifier are 16 features. In the experimental result, the authors compared the previous work of classification KNN and SVM using multi texton histogram [19]. The experimental result showed combination GLCM and SVM is better than previous work.

\section{DATASET}

This study applies a dataset of batik motif images with a total of 300 images. There are 50 classes in the dataset, which consist of 6 batik motif images in each set (with the size of each picture of 180x180 pixels). Figure 1 provides an example of a batik motif image utilized in this paper.

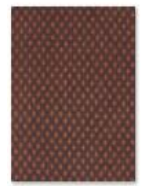

B1_1.jpg

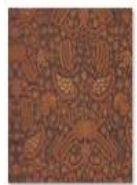

B11_1.jpg
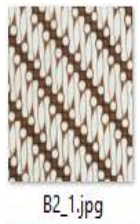

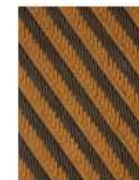

B3_1.jpg

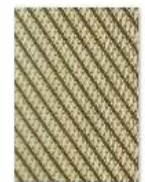

$$
\text { B4_1.jpg }
$$

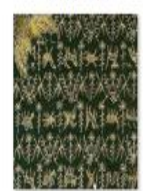

B14_1.jpg

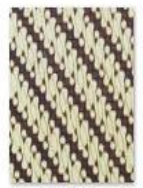

$$
\text { B5_1.jpg }
$$

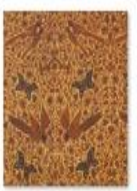

B15_1.jpg

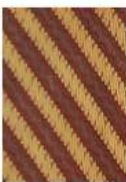

B6_1.jpg

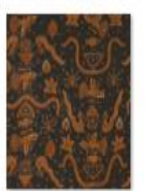

B16_1.jpg

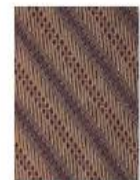

B7_.1.jpg

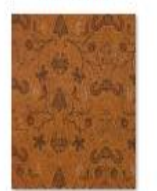

B17_1.jpg

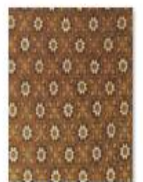

B8_1.jpg

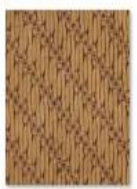

B18_1.jpg

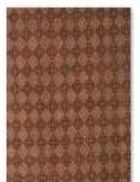

B9_1.jpg

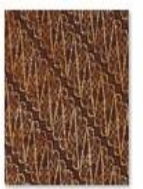

B19_1.jpg

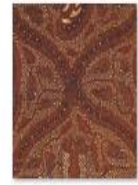

B10_1.jpg

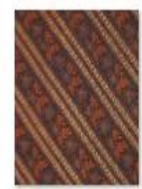

B20_1.jpg

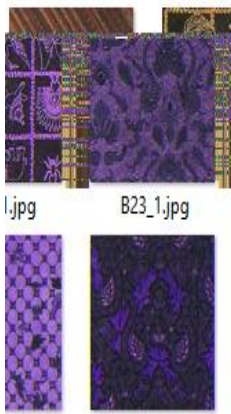

B33_1.jpg

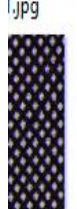

l.jpg

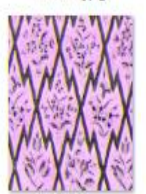

B43_1.jpg

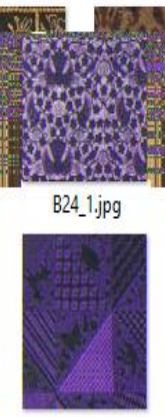

B34_1.jpg

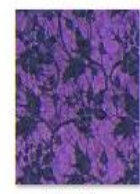

B44_1.jpg
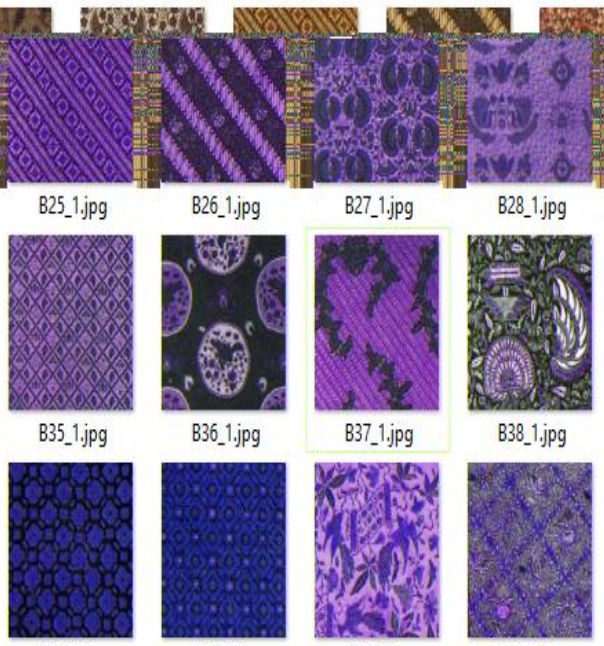

B36_1.jpg
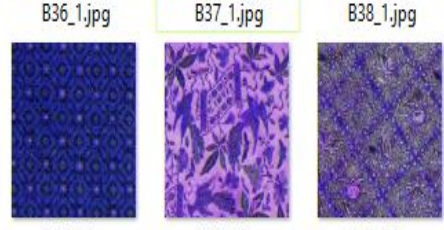

B47_1.jpg

B48_1.jpg
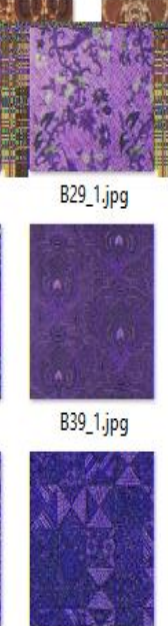

B49_1.jpg

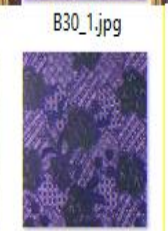

B40_1.jpg

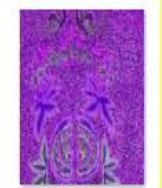

B50_1.jpg
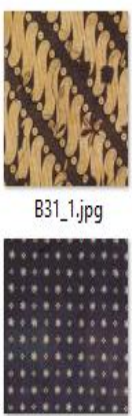

B41_1.jpg

Figure 1. Example of batik patterns 


\section{GRAY LEVEL CO-OCCURENCE MATRIX (GLCM)}

Gray level co-occurrence matrix (GLCM) is defined as a matrix whose elements consist of pairs of pixels having a certain brightness level, where pairs of pixels are separated by distance d, with a $\theta$ angle [19-21]. GLCM is considered as the most common method based on the static approach for texture extraction and GLCM approach usually presented in a symmetrical matrix, increasing the required computational time [22]. GLCM can be calculated with both symmetrical and asymmetrical matrix. The distance in the calculation of GLCM is expressed in pixel units while the angle in the calculation of GLCM is expressed in degrees. Certain angles are often used in GLCM for inter-angle $\left(0^{\circ}, 45^{\circ}, 90^{\circ}\right.$, and $135^{\circ}$ ) calculations [23-25]. Figure 2 provides an illustration of the angle commonly used on GLCM, and Figure 3 provides an illustration of the GLCM.

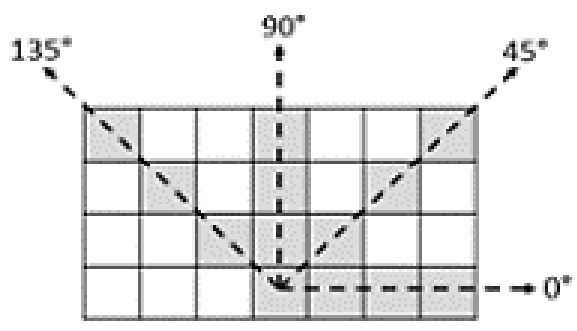

Figure 2. The angles in GLCM

In order to obtain the texture characteristics of an image, features energy, entropy, contrast, and correlation, calculations are extracted from GLCM. The most common statistical calculations used in GLCM include:

Energy:

$$
\begin{aligned}
& \sum_{i, j=0}^{N-1} P_{i, j}^{2} \\
& \sum_{i, j=0}^{N-1} P_{i, j} \log P_{i, j}
\end{aligned}
$$

Contrast:

$$
\sum_{i, j=0}^{N-1} P_{i, j}(i-j)^{2}
$$

Correlation:

$$
\sum_{i, j=0}^{N-1} \frac{\left(i-\mu_{x}\right)\left(j-\mu_{y}\right) p_{i, j}}{\sigma_{x}^{2} \sigma_{y}^{2}}
$$

with:

$$
\begin{array}{rll}
\mathrm{P}_{\mathrm{i}, \mathrm{j}} & = & \text { Normalized pixel value, } \\
\mathrm{i} & = & \text { (i) pixel composition, } \\
\mathrm{j} & = & \text { (j) pixel composition, } \\
\mu_{x} & =\sum_{I, J=0}^{N-1} \quad i \cdot P_{i, j} \\
\mu_{y} & =\sum_{I, J=0}^{N-1} j \cdot P_{i, j} \\
\sigma_{x}^{2} & =\sum_{I, J=0}^{N-1}\left(i-\mu_{x}\right)^{2} \cdot P_{i, j} \\
\sigma_{y}^{2} & =\sum_{I, J=0}^{N-1}\left(i-\mu_{y}\right)^{2} \cdot P_{i, j}
\end{array}
$$


The extraction of features as applied in this paper uses GLCM method as illustrated in Figure 3. This stage aims to get the features contained in batik images as displayed in the histogram. In the first stage as presented in Figure 4, batik image which originally has an RGB colour model changes to a grayscale image, having one channel value in each pixel, with the equal values on the Red, Green, and Blue channels. After grayscale image is obtained in the $2^{\text {nd }}$ stage, the image is quantized to 16 bins to reduce the burden of the computational process. The extracts of GLCM feature at an angle of $0^{\circ}, 45^{\circ}, 90^{\circ}$, and $135^{\circ}$ is obtained in the 3rd stage. Finally, in the $4^{\text {th }}$ stage, the features are stored on the histogram.

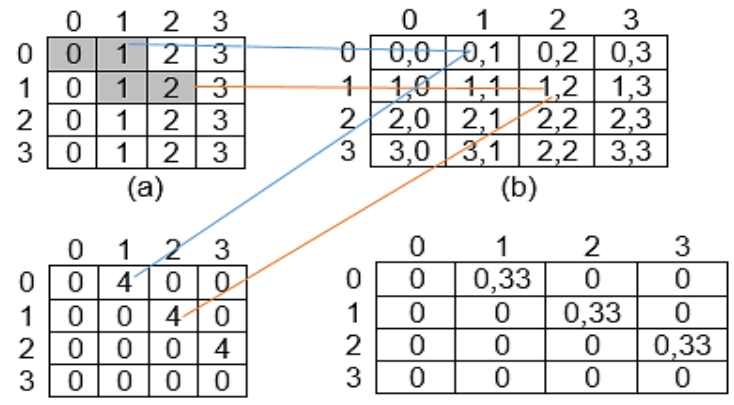

(c) (d)

Figure 3. Illustration of GLCM, (a) Original image, (b) Pixel address, (c) GLCM matrix, (d) GLCM normalization matrix

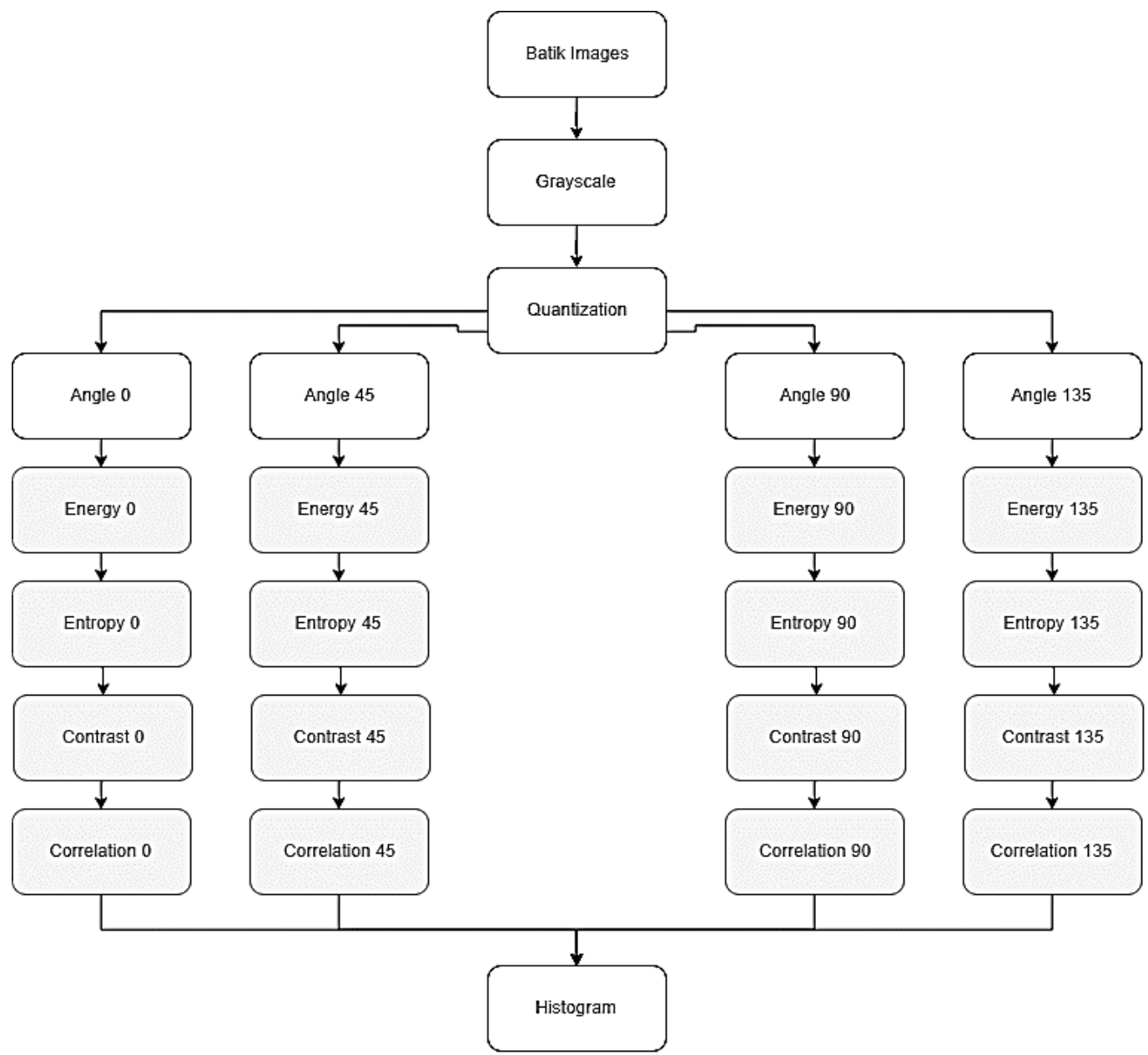

Figure 4. Processing stages in the GLCM method 
Figure 5(a) illustrates one of the images as used in this paper, with a size of $180 \times 180$ pixels. Figure 5(b) presents the result of the grayscale process as carried out in Figure 5, to be used in the quantization process. Figure 5(c) provides the result of the quantization process as carried out in Figure 5. In this paper, the grayscale image is quantized to 16 bin to achieve the pixel value of $0-15$.

Figure 6 depicts the histogram result of GLCM feature extraction in sequential order from the left to the right (angle energy 0 (1), contrast angle 0 (2), entropy of angle 0 (3), correlation angle 0 (4), angle energy 45 (5), angle contrast 45 (6), angle entropy 45 (7), correlation angle 45 (8), angle energy 90 (9), contrast angle 90 (10), entropy angle 90 (11), correlation angle 90 (12), energy angles 135 (13), contrast angles 135 (14), entropy angles 135 (15), and angular correlations 135 (16)). The extracted features that have been obtained are applied for the classification process.

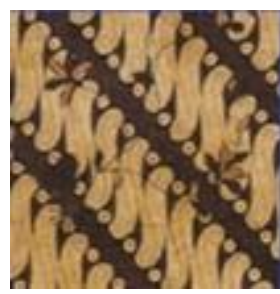

(a)

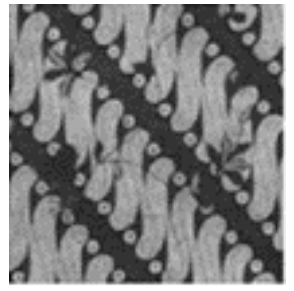

(b)

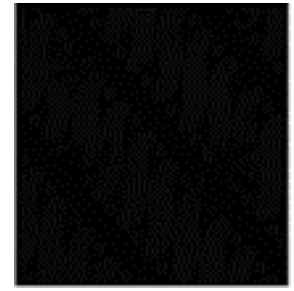

(c)

Figure 5. (a) Batik image, (b) Batik grayscale image, (c) Batik quantization image

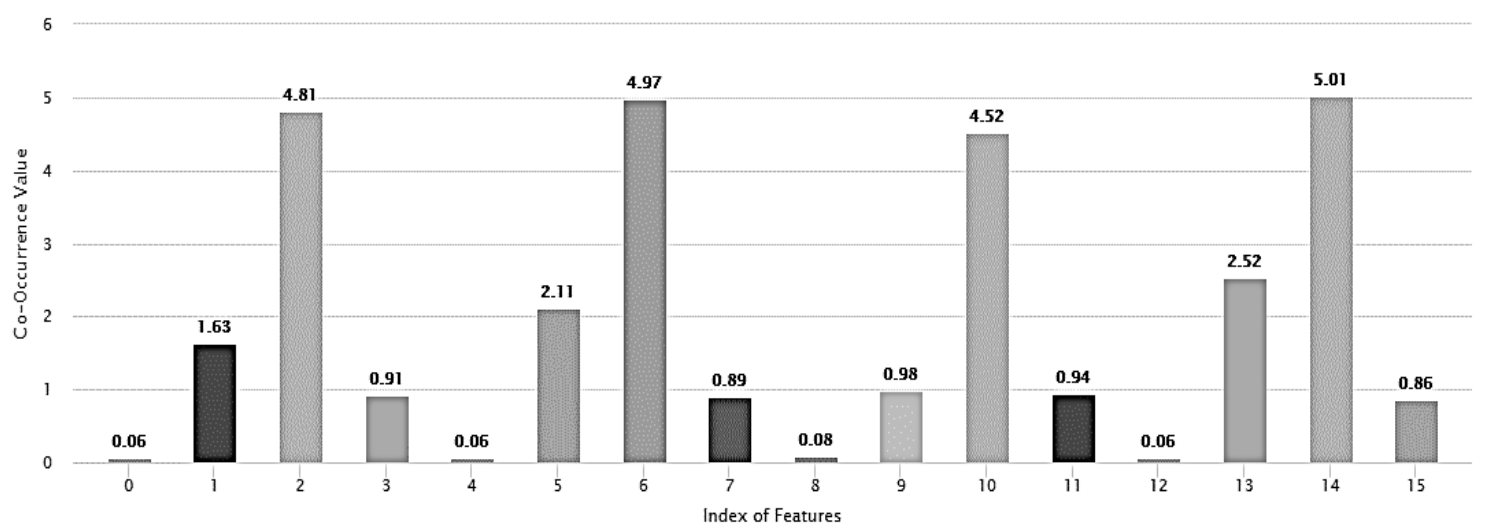

Figure 6. An example GLCM histogram features of batik image in Figure 5

\section{PERFORMANCE MEASUREMENT}

This study applies the calculation of accuracy to measure the performance of the system which has been built with:

$$
\text { Accuracy }=\frac{m}{n} \cdot 100 \%
$$

with:

$$
\begin{aligned}
& \mathrm{m}=\text { Total correct tested data, } \\
& \mathrm{n}=\text { Total tested data }
\end{aligned}
$$

\section{RESULT AND DISCUSSION}

In the first test, 300 data sets of batik motifs are divided into $50 \%$ (150 images) as trained data and 50\% (150 images) as tested data. Table 1 and Table 2 depict the results of shared data testing (50:50). In the second test, 300 data sets of batik motifs are divided into 60\% (200 images) as trained data and $40 \%$ 
(100 images) as tested data. Table 3 and Table 4 show the results of shared data testing (60:40). In the third test, 300 data sets of batik motifs are divided into $80 \%$ (250 images) as trained data and 20\% (50 images) as tested data. Table 5 and Table 6 presents the results of shared data testing (80:20). The fourth test using cross-validation for KNN classification method was conducted by using the parameter of $K=1$ until $K=6$, while for the classification method was performed by using kernel parameter=polynomial with a degree of $=3$ and $c=4$ showed in Table 7 .

The results of testing as performed by the system or application to classify batik motifs are achieved through GLCM method, whose features is extracted from batik motif images, comprising of energy, entropy, contrast, and correlation at $0^{\circ}, 45^{\circ}, 90^{\circ}$, and $135^{\circ}$ which requires an extracting time for the GLCM features with the classification process in 20 seconds. The testing using the cross-validation (K-Fold) scenario, the highest accuracy of KNN algorithm is pointed at $86 \%$ with $\mathrm{K} 5$ and pointed at $100 \%$ with $\mathrm{K} 5$ in SVM algorithm. Previous research used the MTH feature to classify Batik. The classifiers included SVM and KNN. The testing of the previous studies compared between 4 textons and 6 textons using SVM and KNN. The best results were KNN with 6 textons producing the best accuracy of $82 \%$ while the proposed research produced $100 \%$ accuracy shown in Table 8.

Table 1. Test results of $50 \%$ trained data and $50 \%$ tested data by using KNN method

\begin{tabular}{cc}
\hline $\mathrm{k}$ & Accuracy \\
\hline 3 & $70 \%$ \\
5 & $67 \%$ \\
7 & $49 \%$ \\
9 & $44 \%$ \\
\hline
\end{tabular}

Table 3. Test results of $60 \%$ trained data and $40 \%$ tested data by using KNN method

\begin{tabular}{cc}
\hline $\mathrm{k}$ & Accuracy \\
\hline 3 & $67 \%$ \\
5 & $67 \%$ \\
7 & $66 \%$ \\
9 & $53 \%$ \\
\hline
\end{tabular}

Table 5. Test results of $80 \%$ trained data and $20 \%$ tested data by using KNN method

\begin{tabular}{cc}
\hline $\mathrm{k}$ & Accuracy \\
\hline 3 & $66 \%$ \\
5 & $60 \%$ \\
7 & $62 \%$ \\
9 & $56 \%$ \\
\hline
\end{tabular}

Table 2. Test results of 50\% trained data and 50\% tested data by using the SVM method

\begin{tabular}{ccccc}
\hline Kernel & Degree & C & Gamma & Accuracy \\
\hline Poly & 3 & 4 & - & $76 \%$ \\
Poly & 3 & 8 & - & $76 \%$ \\
Poly & 3 & 16 & - & $76 \%$ \\
Poly & 4 & 4 & - & $75.33 \%$ \\
Poly & 5 & 4 & - & $75.33 \%$ \\
poly & 6 & 4 & - & $74 \%$ \\
Linier & - & 4 & - & $74.66 \%$ \\
Linier & - & 8 & - & $78 \%$ \\
Linier & - & 16 & - & $78.66 \%$ \\
RBF & - & 4 & 1 & $74.66 \%$ \\
RBF & - & 4 & 2 & $74.66 \%$ \\
RBF & - & 4 & 3 & $74.66 \%$ \\
RBF & - & 4 & 4 & $75.33 \%$ \\
\hline
\end{tabular}

Table 4. Test results of $60 \%$ trained data and $40 \%$ tested data by using the SVM method

\begin{tabular}{ccccc}
\hline Kernel & Degree & C & Gamma & Accuracy \\
\hline Poly & 3 & 4 & - & $86 \%$ \\
Poly & 3 & 8 & - & $86 \%$ \\
Poly & 3 & 16 & - & $84 \%$ \\
Poly & 4 & 4 & - & $85 \%$ \\
Poly & 5 & 4 & - & $85 \%$ \\
poly & 6 & 4 & - & $85 \%$ \\
Linier & - & 4 & - & $78 \%$ \\
Linier & - & 8 & - & $81 \%$ \\
Linier & - & 16 & - & $84 \%$ \\
RBF & - & 4 & 1 & $76 \%$ \\
RBF & - & 4 & 2 & $77 \%$ \\
RBF & - & 4 & 3 & $79 \%$ \\
RBF & - & 4 & 4 & $79 \%$ \\
\hline
\end{tabular}

Table 6. Test results of $80 \%$ trained data and $20 \%$ tested data by using the SVM method

\begin{tabular}{ccccc}
\hline Kernel & Degree & C & Gamma & Accuracy \\
\hline Poly & 3 & 4 & - & $76 \%$ \\
Poly & 3 & 8 & - & $76 \%$ \\
Poly & 3 & 16 & - & $76 \%$ \\
Poly & 4 & 4 & - & $78 \%$ \\
Poly & 5 & 4 & - & $80 \%$ \\
poly & 6 & 4 & - & $80 \%$ \\
Linier & - & 4 & - & $74 \%$ \\
Linier & - & 8 & - & $74 \%$ \\
Linier & - & 16 & - & $76 \%$ \\
RBF & - & 4 & 1 & $76 \%$ \\
RBF & - & 4 & 2 & $76 \%$ \\
RBF & - & 4 & 3 & $76 \%$ \\
RBF & - & 4 & 4 & $78 \%$ \\
\hline
\end{tabular}


Table 7. The scenario of cross-validation testing result

\begin{tabular}{|c|c|c|c|c|c|c|c|}
\hline & \multicolumn{6}{|c|}{ Accuracy } & \multirow{2}{*}{ Mean } \\
\hline & $\mathrm{K}=1$ & $\mathrm{~K}=2$ & $K=3$ & $\mathrm{~K}=4$ & $\mathrm{~K}=5$ & $\mathrm{~K}=6$ & \\
\hline KNN & $66 \%$ & $82 \%$ & $76 \%$ & $78 \%$ & $86 \%$ & $82 \%$ & $78.3 \%$ \\
\hline SVM & $76 \%$ & $98 \%$ & $94 \%$ & $90 \%$ & $100 \%$ & $96 \%$ & $92.3 \%$ \\
\hline
\end{tabular}

Table 8. The comparison with the previous work [19]

\begin{tabular}{cccc}
\hline & \multicolumn{3}{c}{ Accuracy } \\
\cline { 2 - 4 } & MTH 4 Textons & MTH 6 Textons & Proposed Method \\
\hline KNN & $70 \%$ & $82 \%$ & $86 \%$ \\
SVM & $64 \%$ & $76 \%$ & $100 \%$ \\
\hline
\end{tabular}

\section{CONCLUSION}

This study proposed a system to classify batik motif images by using grey-level co-occurrence matrix (GLCM) method. The average accuracy obtained in testing with cross-validation scenario reached 92.3\% for SVM and $78.3 \%$ for KNN. Meanwhile, the highest accuracy in testing with a shared data scenario reached $86 \%$ for SVM and $70 \%$ for KNN. Based on the results of testing, the classification using GLCM and SVM method considered as the effective and reliable approach for recognizing batik pattern images which were better than previous work (MTH and SVM).

\section{ACKNOWLEDGEMENTS}

This research was supported by Laboratorium Informatika Universitas Muhammadiyah Malang.

\section{REFERENCES}

[1] A. E. Minarno, Y. Munarko, and A. Kurniawardhani, "CBIR of batik images using micro structure descriptor on android," International Journal of Electrical and Computer Engineering (IJECE), vol. 8, no. 5, pp. 3778-3783, 2018.

[2] Y. Munarko \& A. E. Minarno, "HII: Histogram inverted index for fast images retrieval," International Journal of Electrical and Computer Engineering (IJECE), vol. 8, no. 5, pp. 3140-3148, 2018.

[3] H.Prasetyo, W. Wiranto, W. Winarno, U. Salamah, and B. Harjito, "Batik image retrieval using ODBTC feature and particle swarm optimization," Journal of Telecommunication, Electronic and Computer Engineering (JTEC), vol. 10, no. 2-4, pp. 71-74, 2018.

[4] Q. Yuan, S. Xu, and L. Jian, "A new method for retrieving batik shape patterns," Journal of the Association for Information Science and Technology, vol. 69, no. 4, pp. 578-599, 2018.

[5] A. Kurniawardhani, A. E. Minarno, and F. Bimantoro, "Efficient texture image retrieval of improved completed robust local binary pattern," International Conference on Advanced Computer Science and Information Systems (ICACSIS), pp. 492-497, 2016.

[6] G. A. Pradnyana, Suryantara I. K. A., \& Darmawiguna I. G. M., "Impression classification of endek (Balinese fabric) image using K-nearest neighbors method," Kinetik: Game Technology, Information System, Computer Network, Computing, Electronics, and Control, vol. 3, no. 3, pp. 213-220, 2018.

[7] E. Prasetyo, R. D. Adityo, N. Suciati, and C. Fatichah, "Multi-class K-support vector nearest neighbor for mango leaf classification," TELKOMNIKA Telecommunication Computing Electronics and Control, vol. 16, no. 4, pp. 1826-1837, 2018.

[8] A. E. Minarno, Y. Munarko, A. Kurniawardhani, F. Bimantoro, and N. Suciati, "Texture feature extraction using co-occurrence matrices of sub-band image for batik image classification," 2nd International Conference on Information and Communication Technology (ICoICT), pp. 249-254, May 2014.

[9] M. Arebey, M. A. Hannan, H. Basri, and R. A. Begum, "Bin level detection using gray level co-occurrence matrix in solid waste collection," Proceedings of the World Congress on Engineering and Computer Science, 2012.

[10] Nurhaida I., Manurung R., \& Arymurthy A. M., "Performance comparison analysis features extraction methods for batik recognition," International Conference on Advanced Computer Science and Information Systems (ICACSIS), pp. 207-212, 2012.

[11] A. E. Minarno and N. Suciati, "Image retrieval using multi texton co-occurrence descriptor," Journal of Theoretical \& Applied Information Technology, vol. 67, no. 1, 2014.

[12] A. Fahrurozi, S. Madenda, D. Kerami, "Wood texture features extraction by using glcm combined with various edge detection methods," Journal of Physics: Conference Series, vol. 725, no. 1, pp. 1-11, 2016.

[13] H. Y. Chai, L. K. Wee, T. T. Swee, S. H. Salleh, and A. K. Ariff, "Gray-level co-occurrence matrix bone fracture detection," American Journal of Applied Sciences, vol. 8, no, 1, pp. 7-16, 2011.

[14] A. K. Mohanty, S. Beberta, and S. K. Lenka, "Classifying benign and malignant mass using glcm and glrlm based texture features from mammogram," International Journal of Engineering Research and Applications, vol. 1, no. 3, pp. 687-693, 2011. 
[15] N. Zulpe and V. Pawar, "Glcm textural features for brain tumor classification," Int. J. Comput. Sci, vol. 9, no. 3, pp. 354-359, 2012.

[16] R. Hudec, and M. Benco, "Novel method for color textures features extraction based on Glcm," Radioengineering, vol. 16, no. 4, pp. 64-67, 2007.

[17] J. L. Raheja, S. Kumar, and A. Chaudhary, "Fabric defect detection based on Glcm and gabor filter: A comparison," Optik-International Journal for Light And Electron Optics, vol. 124, no. 23, pp. 6469-6474, 2013.

[18] Mitrea D., Socaciu M., Badea R., \& Nedevschi S., "The role of the superior order Glcm in the characterization and recognition of the liver tumors from ultrasound images," Radioengineering, vol. 21, no. 1, pp.79-85, 2012.

[19] A. E. Minarno, A. S. Maulani, A. Kurniawardhani, F. Bimantoro, and N. Suciati, "Comparison of methods for batik classification using multi texton histogram," TELKOMNIKA Telecommunication Computing Electronics and Control, vol. 16, no. 3, pp. 1358-1366, 2018.

[20] A. E. Minarno, A. Kurniawardhani, and F. Bimantoro, "Image retrieval based on multi structure co-occurrence descriptor," TELKOMNIKA Telecommunication Computing Electronics and Control, vol. 14, no. 3, pp. 252-258, 2016.

[21] H. Wibowo, E. M. Yuniarno, A. Widayati, and M. H. Purnomo, "Frontalis muscle strength calculation based on 3D image using gray level co-occurrence matrix (GLCM) and confidence interval," TELKOMNIKA Telecommunication Computing Electronics and Control, vol. 16, no. 1, pp. 368-375, 2018

[22] N. D. Abdullah, U. R. A. Hashim, S. Ahmad, and L. Salahuddin, "Analysis of texture features for wood defect classification," Bulletin of Electrical Engineering and Informatics, vol. 9, no. 1, pp. 121-128, 2020.

[23] F. I. M. Redzuan and M. Yusoff, "Knots timber detection and classification with c-support vector machine," Bulletin of Electrical Engineering and Informatics, vol. 8, no. 1, pp. 246-252, 2019.

[24] E. M. Yuniarno and M. H. Purnomo, "Indonesian batik image classification using statistical texture feature extraction gray level co-occurrence matrix (GLCM) and learning vector quantization (LVQ)," Journal of Telecommunication, Electronic and Computer Engineering (JTEC), vol. 10, no. 2-3, pp. 67-71, 2018.

[25] N. Sulistianingsih, I. Soesanti, and R. Hartanto, "Classification of batik image using grey level co-occurrence matrix feature extraction and correlation based feature selection," International Seminar on Research of Information Technology and Intelligent Systems (ISRITI) IEEE, pp. 492-497, 2018. 